\title{
A necessidade de regulamentação multilaretal do comércio internacional: protecionismo x liberalização
}

Marlon Tomazette ${ }^{1}$

\section{Resumo}

O presente artigo tem como objetivo mostrar a necessidade da convivência da liberalização do comércio com práticas protecionistas, por meio da regulamentação multilateral do comércio. A economia globalizada revela uma relação de interdependência entre as várias economias nacionais. Essa relação de interdependência impõe a existência de regras internacionais que regulamentam as atividades comerciais que se desenvolvam. Não há que se falar em desregulamentação. Tal regulamentação deve ser multilateral diante da realidade atual do mundo. Para tal regulamentação multilateral prevalecem os valores do livre comércio como meta a ser alcançada em busca de paz entre as nações e de um desenvolvimento sustentável. Todavia, a definição de valores pró-liberalização deve admitir concessões protecionistas, diante da realidade distinta de cada um dos países inseridos no mercado global.

Palavras-chave: Comércio internacional. Globalização. Protecionismo. Livre comércio. Multilateralismo.

\section{Introdução}

A globalização econômica enseja a formação de um mercado mundial que deve ser objeto de regulamentação multilateral no sentido da liberalização do comércio sem deixar de garantir a aplicação de certas medidas protecionistas. Ao contrário do que se costuma asseverar, o atual processo de globalização impõe

\footnotetext{
${ }^{1}$ Mestre e Doutorando em Direito no Centro Universitário de Brasília - UniCEUB, Professor de direito empresarial no UniCEUB e na Escola Superior do Ministério Público. Procurador do DF e Advogado.
} 
uma regulamentação multilateral do comércio internacional, pautada por princípios que militam no sentido da liberalização comercial fazendo certas concessões ao protecionismo. Tal fato decorre, sobretudo, da atual realidade que se apresenta, no sentido de uma globalização econômica, na qual os vínculos de interdependência entre as várias economias nacionais se mostram cada vez mais fortes. Nessa regulamentação devem ser feitas algumas concessões, permitindo medidas de certo modo protecionistas nos casos em que ocorra uma distorção do comércio internacional.

A atividade comercial, em especial o comércio internacional, vem cada vez mais se difundindo por diversos motivos capazes inclusive de gerar grandes transformações na sociedade mundial. A partir da ideia de um sistema econômico mundial, será estudado o fenômeno da globalização, mais especificamente da globalização econômica, buscando demonstrar a existência de um mercado mundial, no qual se desenvolvem as atividades comerciais. Nesse mercado mundial, é fundamental reconhecer a existência de laços entre as diversas economias nacionais, configurando algo que pode ser chamado de interdependência.

Essa realidade impõe a adoção de medidas que regulamentem a atividade comercial em nível internacional, não apenas à economia, mas para esse mercado global. Nessa regulamentação há um debate sobre os valores que devem predominar, sejam os valores do livre comércio ou os valores do protecionismo. Dentro desse debate, há justificativas de um lado e de outro para essa ou aquela opção.

Diante do mundo globalizado, essa regulamentação e esse debate se resolvem no sentido da adoção de acordos multilaterais de comércio, como mecanismos reguladores da vida econômica das nações, sendo a criação da OMC um marco importante nesse processo. A liberalização do comércio é um valor inerente à regulamentação multilateral e por isso pauta suas normas e princípios.

Vislumbra-se nos princípios da regulamentação multilateral do comércio toda a tendência pró-liberalização que decorre da realidade atual do mundo, em especial da interdependência entre as várias economias nacionais. Todavia, esse viés não pode ser adotado de forma absoluta, devendo comportar algumas ex- 
ceções que se justifiquem para evitar uma distorção do comércio. Tais medidas, embora protecionistas, mostram-se como condições para se alcançar progressivamente a liberalização e torná-la politicamente possível.

Para atender tais objetivos, foi realizada pesquisa documental na doutrina nacional e estrangeira.

\section{0 desenvolvimento do comércio internacional}

A palavra comércio tem sua origem no latim commutatio mercium, que significa troca de mercadorias por mercadorias. Tal troca tornou-se um elemento fundamental para o convívio em sociedade desde os tempos mais remotos, porquanto era cada vez mais difícil a autossatisfação de todas as necessidades de uma pessoa pertencente a um determinado grupo social, ou ao menos era mais cômoda a troca. A desejada autossuficiência dos grupos sociais foi aos poucos se mostrando problemática, fazendo surgir essa troca de mercadorias.

Em função da importância que essa troca de mercadorias assumiu, surgiu uma atividade profissional nesse sentido, isto é, algumas pessoas tinham por profissão promover tal troca. Como afirma Vivante, “a indústria comercial compreende todos os atos que se destinam a reunir as provisões nos lugares onde são necessárias, na qualidade e quantidade precisas em tempo oportuno". ${ }^{2}$

A atividade comercial que sempre existiu foi se desenvolvendo cada vez mais, ganhando importância fundamental tanto econômica como politicamente, e gerando uma grande mudança na sociedade mundial.

A queda do império romano e, consequentemente, a ausência de um poder estatal centralizado fizeram surgir pequenas cidades, que não eram autossuficientes para atender suas necessidades, as quais se mantiveram fechadas durante toda a

2 VIVANTE, Cesare. Instituições de direito comercial. Tradução de J. Alves de Sá. 3. ed. São Paulo: C. Teixeira, 1928. p. 23. 
Idade Média. ${ }^{3}$ Por volta dos séculos XI e XII, com a reabertura das vias comerciais do norte e do sul da Europa, desenvolveu-se uma mudança radical na configuração da sociedade, uma grande imigração do campo, formando-se cidades como centros de consumo, de troca e de produção industrial.

Essa mudança foi provocada pela crise do sistema feudal, resultado da subutilização dos recursos do solo, da baixa produtividade do trabalho servil aliada ao aumento da pressão exercida pelos senhores feudais sobre a população. Em função da citada crise houve uma grande migração que envolvia, dentre outros, os mercadores ambulantes, que viajavam em grupos e conseguiram um capital inicial que permitiu a estabilização de uma segunda geração de mercadores nas cidades, desenvolvendo um novo modo de produção, ${ }^{4}$ o mercantilismo.

Com o crescimento demográfico nas cidades e o consequente excesso de oferta de mão de obra, houve um aumento na produção que desenvolveu as cidades e o comércio internacional, mobilizando grandes quantidades de capitais. Neste momento, a burguesia ascendente se associa à nobreza e forma os chamados estados absolutistas, ainda não desvinculados completamente da Igreja, mas já havendo um grande declínio do poder desta em função de um início da separação entre o poder político e poder secular, fortemente influenciado pela reforma protestante.

A formação do Estado moderno que se inicia nesse período, conclui-se com transformações que ocorrem dentro do próprio Estado em consequência de movimentos revolucionários, especialmente na França, na Inglaterra e nos Estados Unidos durante os séculos XVII e XVIII, ${ }^{5}$ formando o que se convencionou denominar de Estados Nacionais ou Estados Nação.

${ }^{3}$ GALGANO, Francesco. História do direito comercial. Tradução de João Espírito Santo. Lisboa: PF, 1990. p. 31.

4 GALGANO, Francesco. História do direito comercial. Tradução de João Espírito Santo. Lisboa: PF, 1990. p. 32.

5 JELLINEK, Georg. Teoria general del Estado. Traducción por Fernando de Los Rios Urruti. Granada: Comares, 2000. p. 320. 
O desenvolvimento da atividade comercial, determinante na formação dos Estados Nacionais, não se realizava de modo constante nem uniforme nesses vários Estados. Alguns desenvolviam essa atividade melhor que outros. Dada a própria natureza da atividade comercial, é certo que ela não poderia se restringir a fronteiras previamente definidas, isto é, a atividade comercial desenvolveu-se, sobretudo, em nível internacional.

Como os países são diferentes ${ }^{6}$ e têm condições diferentes de realização da atividade comercial, é natural que o comércio se desenvolva entre diversos países de acordo com as melhores condições de cada um. É certo também que há vantagens inerentes à especialização de cada país em certo ramo da produção, ${ }^{7}$ o que se explica pela chamada teoria das vantagens comparativas. De acordo com essa teoria, o comércio internacional permite a utilização mais eficiente dos recursos econômicos, visto que possibilita a importação de bens e serviços que, de outra forma, só poderiam ser produzidos internamente a um custo superior; vale dizer que o comércio internacional permite aos consumidores o acesso a produtos a melhor preço.

Em função de tudo isso, o comércio internacional desenvolveu fortemente no mundo, gerando uma série de efeitos sobre as economias nacionais, que se tornaram cada vez mais abertas, aumentando o fluxo de produção de um país a outro. Em especial no período pós-Segunda Guerra, começa a se verificar a existência de uma intensa rede mundial de relações comerciais entre os diversos países. ${ }^{8}$

\section{Globalização econômica e interdependência}

Com o fenômeno da globalização, o comércio internacional se desenvolve cada vez mais, aflorando como uma realidade inegável a relação de interdependência

6 KRUGMAN, Paul R. Rethinking international trade. Massachussets: The Mit Press, 1990. p. 2. 7 KRUGMAN, Paul R. Rethinking international trade. Massachussets: The Mit Press, 1990. p. 2.

8 OLIVEIRA, Odete Maria de. Relações comerciais globais e o império dos mercados mundiais. In: OLIVEIRA, Odete Maria de; DAL RI JÚNIOR, Arno (Org.). Direito internacional econômico em expansão: desafios e dilemas. Ijuí: Unijuí, 2003. p. 843-951. p. 928. 
entre as várias economias nacionais. Esses laços de interdependência impõem que se faça uma regulamentação dessa atividade.

Uma das expressões mais usadas atualmente para justificar as tensões do fim do século XX e do início do século XXI é a expressão globalização. Essa expressão não tem um único sentido, mas vários sentidos ${ }^{9}$, que dizem respeito à economia, à política e à própria soberania dos Estados.

A globalização é uma expressão de sentido bastante variado. Ela representa “a ação sem fronteiras nas dimensões da economia, da informação, da ecologia, da técnica, dos conflitos transculturais e da sociedade civil”, ${ }^{10}$ ou como afirma Habermas a "intensificação dos fenômenos de troca, de comunicação e de trânsito para além das fronteiras nacionais". ${ }^{11}$ As ideias, os efeitos e as práticas que resultam da globalização são extremamente variados, daí poder-se falar em globalizações.

Para o presente trabalho, interessa a globalização econômica, que pode ser entendida como a "interligação de mercados nacionais através do aumento da circulação entre eles de bens, serviços e capitais". ${ }^{12}$ Em outras palavras, ela consiste na “integração das economias nacionais em uma economia internacional através do comércio, do investimento estrangeiro direto (por parte de corporações e multinacionais), fluxos de capital de curto prazo, fluxo internacional de trabalhadores e pessoas em geral e fluxos de tecnologia”. ${ }^{13}$

9 FARIA, José Eduardo. O direito na economia globalizada. São Paulo: Malheiros, 2000. p. 59; BHAGWATI, Jagdish. Em defesa da globalização. Tradução de Regina Lyra. Rio de Janeiro: Elsevier, 2004. p. 3; ALMEIDA, Paulo Roberto de. A globalização e o desenvolvimento: vantagens e desvantagens de um processo indomável. In: DI SENA JÚNIOR, Roberto; CHEREM, Mônica Teresa Costa (Org.). Comércio internacional e desenvolvimento: uma perspectiva brasileira. São Paulo: Saraiva, 2004. p. 17-31. p. 18.

${ }^{10}$ BECK, Ulrich. O que é a globalização? Tradução de André Carone. São Paulo: Paz e Terra, 1999. p. 46.

${ }^{11}$ HABERMAS, Jürgen. A constelação pós-nacional: ensaios políticos. Tradução de Márcio Seligmann- Silva. São Paulo: Littera Mundi, 2001. p. 84.

${ }^{12}$ NUSDEO, Ana Maria de Oliveira. Defesa da concorrência e globalização econômica: o controle da concentração de empresas. São Paulo: Malheiros, 2002. p. 137-138.

${ }^{13}$ BHAGWATI, Jagdish. Em defesa da globalização. Tradução de Regina Lyra. Rio de Janeiro: Elsevier, 2004. p. 3-4. 
Em suma, a globalização econômica representa a formação de um mercado mundial, no qual há um aumento do fluxo de pessoas, de bens, de serviços, de capitais e de informações. Essa é apenas uma das acepções do fenômeno da globalização, mas é a acepção que interessa para identificação dos efeitos dela sobre a regulamentação do comércio internacional.

Esse fenômeno da globalização econômica é uma realidade atual que tem gerado uma série de efeitos, em especial, "a alteração da estratégia competitiva das empresas, a dispersão internacional das etapas do processo produtivo, a homogeneização dos hábitos de consumo e de práticas comerciais, a desregulamentação dos mercados financeiros e de outros setores da economia nacionais e, a formação de blocos regionais de livre comércio". ${ }^{14}$ Dentre todos os efeitos, vê-se claramente a formação de um mercado unificado, no qual os mesmos produtos são vendidos e as mesmas imagens e informações são transmitidas.

Essa globalização, nas palavras do professor Paulo Roberto de Almeida, "se faz presente, em primeiro lugar, mediante as relações financeiras e de comércio que os países mantêm entre si, mas é pelo setor produtivo que ela é suscetível de impactar mais decisivamente o perfil e a própria estrutura das economias nacionais". ${ }^{15}$ Ela influi decisivamente nas relações comerciais existentes, porquanto o mercado agora é maior, os competidores estão presentes em todo o mundo, realizando transações em massa e a todo o momento. Tal realidade afeta as próprias economias nacionais, que têm que se adaptar, adotando medidas que permitam a atuação nesse mercado global.

A globalização gera um acirramento da concorrência, que obriga as empresas cada vez mais a elevar a sua produtividade e a racionalizar o processo de trabalho. Diante dessa realidade, não resta outro caminho às empresas, senão o de

\footnotetext{
${ }^{14}$ NUSDEO, Ana Maria de Oliveira. Defesa da concorrência e globalização econômica: o controle da concentração de empresas. São Paulo: Malheiros, 2002. p. 138.

${ }^{15}$ ALMEIDA, Paulo Roberto de. A globalização e o desenvolvimento: vantagens e desvantagens de um processo indomável. In: DI SENA JÚNIOR, Roberto; CHEREM, Mônica Teresa Costa (Org.). Comércio internacional e desenvolvimento: uma perspectiva brasileira. São Paulo: Saraiva, 2004. p. 17-31. p. 21.
} 
acompanhar o fenômeno da globalização, a fim de que não fiquem obsoletas e não sejam excluídas do mercado. ${ }^{16}$ Para tanto, as empresas devem crescer, expandindo sua atuação, até para além de suas fronteiras originais. Giampaolo Dalle Vedove afirma que, nessa realidade, as empresas buscam "crescer em poder, para adquirir uma dimensão comunitária e se possível mundial”. ${ }^{17}$

A existência de um mercado mundial e a expansão da atuação das empresas demonstram que a ideia da autarquia como um Estado possível ou mesmo desejável deve ser descartada no mundo real. Nenhum Estado é capaz de suprir todas as suas necessidades. Tal realidade implica a existência de laços entre as economias de vários países. Sobretudo com a globalização, esses laços entre as economias nacionais vêm ficando cada vez mais estreitos, com a expansão da atuação das empresas multinacionais, de modo que pode se falar hoje em interdependência, para descrever as relações econômicas internacionais. ${ }^{18}$

A interdependência pauta todas as relações econômicas contemporâneas e traz à tona a complementaridade existente entre as várias economias nacionais. ${ }^{19}$ Uma economia depende da outra e vice-versa. Não há economia que sobreviva sem tais ligações. As economias nacionais são cada vez mais afetadas pelos "equilíbrios externos e pelos vínculos de interdependência que se estabelecem em escala planetária". ${ }^{20}$

Essa realidade impõe a adoção de medidas que regulamentem a atividade comercial em nível internacional, não apenas para uma economia, mas para esse mercado global. Todavia, isso não significa que haja uma igualdade entre as várias

${ }^{16}$ FERRAZ, Daniel Amin. Joint venture e contratos internacionais. Belo Horizonte: Mandamentos, 2001. p. 168.

${ }^{17}$ VEDOVE, Giampaolo Dalle. Concentrazioni e gruppi nel diritto antitrus. Padova: CEDAM, 1999. p. 96. Tradução livre de "crescere in potere, per acquistare uma dimensione comunitaria e se possibile mondiale".

${ }^{18}$ ALMEIDA, Paulo Roberto de. O Brasil e o multilateralismo econômico. Porto Alegre: Livraria do Advogado, 1999. p. 34.

${ }^{19}$ ALMEIDA, Paulo Roberto de. O Brasil e o multilateralismo econômico. Porto Alegre: Livraria do Advogado, 1999. p. 39.

${ }^{20}$ ALMEIDA, Paulo Roberto de. O Brasil e o multilateralismo econômico. Porto Alegre: Livraria do Advogado, 1999. p. 35. 
economias. A desigualdade é gigantesca e reinante no chamado sistema econômico mundial que se forma.

Em cada Estado, as reações e iniciativas no sentido dessa regulamentação são diversas, ora no sentido da liberalização, ora no sentido da adoção de medidas protecionistas, num processo cíclico que se explica pelos próprios ciclos de crescimento e recessão do capitalismo. ${ }^{21}$ Em qualquer caso, mostra-se fundamental a adoção de certa regulamentação em nível internacional, na qual predominem valores do livre comércio ou os valores do protecionismo.

\section{Regulamentação do comércio internacional}

A necessidade de regulamentação do comércio internacional se torna cada vez mais patente, sobretudo nesse período de globalização, no qual a relação de interdependência entre as várias economias nacionais se mostra cada vez mais forte. Nesse processo, os governos nacionais não têm o mesmo poder que possuíam na órbita interna, na medida em que tal regulamentação depende de negociação com outros Estados, cada qual com uma realidade distinta e com poderes distintos para a negociação.

\subsection{Protecionismo}

A princípio, a atividade comercial é uma atividade privada e deveria desenvolver-se livremente, sem imposições de restrições por parte do Estado. Todavia, é certo que o comércio internacional pode gerar uma série de efeitos, sobre os produtores nacionais, efeitos estes que nem sempre são desejados por eles. Em função disso, desde o surgimento dos Estados nacionais é freqüente a reivindicação da intervenção estatal, para impedir esses efeitos indesejados. Essa intervenção é o que se costuma denominar de protecionismo.

${ }^{21}$ BARRAL, Welber. Protecionismo e neoprotecionismo no comércio internacional. In: (Org.). O Brasil e o protecionismo. São Paulo: Aduaneiras, 2002. p. 13-38. p. 13. 
O protecionismo pode ser entendido "como a utilização de medidas visando à modificação de um fluxo comercia, buscando favorecer produtores nacionais" ${ }^{22}$ Em outros termos, o protecionismo envolve a adoção de medidas que alteram o desenvolvimento normal da atividade comercial, afetando determinados comerciantes, normalmente estrangeiros, em benefício de outros, normalmente nacionais.

As medidas protecionistas podem ser classificadas em barreiras tarifárias e não-tarifárias. ${ }^{23}$

As primeiras atuam por meio da adoção de tarifas aduaneiras sobre os produtos importados, aumentando o preço destes e incentivando o consumo de produtos nacionais. A adoção ou majoração de tributos incidentes sobre a importação de mercadorias encarece os produtos importados, diminuindo sua competitividade em face dos produtos nacionais.

Já as barreiras não tarifárias abrangem uma gama variada de medidas, com o intuito de restringir o acesso dos produtos importados ao mercado nacional. Elas podem impedir a importação, ou impor limites máximos, quotas de importação. Elas também podem atuar impondo exigências adicionais ao produto estrangeiro, encarecendo sua importação. Há ainda a concessão de ajuda estatal aos produtores nacionais, como a concessão de subsídios que facilita a competitividade destes em face dos produtos estrangeiros. Trata-se do chamado protecionismo regulatório que representa qualquer desvantagem em termos de custos imposta a empresas estrangeiras, por meio de uma política de regulamentação que as discrimine ou as coloque em desvantagem, comparativamente aos competidores nacionais. ${ }^{24}$ São exemplos de barreiras não tarifárias, as barreiras técnicas e as barreiras fitossanitárias, dentre outros.

${ }^{22}$ BARRAL, Welber. Protecionismo e neoprotecionismo no comércio internacional. In: (Org.). O Brasil e o protecionismo. São Paulo: Aduaneiras, 2002. p. 13-38. p. 14.

${ }_{23}$ BARRAL, Welber. Protecionismo e neoprotecionismo no comércio internacional. In: (Org.). O Brasil e o protecionismo. São Paulo: Aduaneiras, 2002. p. 13-38. p. 15.

${ }^{24}$ LOCATELLI, Liliana. A proteção ao consumidor como uma barreira ao livre comércio. In: BARRAL, Welber (Org.). O Brasil e o protecionismo. São Paulo: Aduaneiras, 2002. p. 89-116. p. 90. 
Qualquer que seja o tipo de medida protecionista adotada, ela tem que se justificar, uma vez que a sua adoção acaba prejudicando os consumidores que teriam acesso a mais produtos e com preços melhores.

Todavia, essa justificativa não é difícil, tendo em vista a atuação de grupos de pressão organizados, que geram na população a percepção de que o produto estrangeiro está de alguma forma fazendo uma concorrência injusta com os produtores nacionais. ${ }^{25}$ Além disso, as medidas protecionistas são usadas por vezes como formas de punição nas relações entre Estados, ou ainda podem decorrer de acordos de integração regional, no sentido da uniformização de restrições a países que não fazem parte do acordo. ${ }^{26}$

As justificativas propriamente ditas para a adoção de medidas protecionistas envolvem basicamente a proteção do emprego, a proteção à indústria nacional incipiente e a manutenção de estruturas socioculturais. ${ }^{27}$ Tais justificativas são apresentadas pelos defensores de tais medidas, o que não significa que tais medidas sejam realmente justificáveis.

O desemprego, em geral, sempre foi uma grande preocupação da sociedade. Permitir livremente o ingresso de produtos importados diminuiria a utilização da mão de obra local provocando desemprego, na medida em que os produtos importados tornariam desnecessária a produção nacional. Assim, em tese, adotar medidas protecionistas incentivaria o uso da mão de obra local, evitando o desemprego.

De outro lado, a justificativa mais comum para a adoção de medidas protecionistas diz respeito à proteção à indústria nacional nascente, que se encontra ameaçada pelos concorrentes estrangeiros. Nessa situação, o protecionismo seria temporário, duraria apenas o suficiente para que a indústria nascente pudesse con-

${ }^{25}$ BARRAL, Welber. Protecionismo e neoprotecionismo no comércio internacional. In: (Org.). O Brasil e o protecionismo. São Paulo: Aduaneiras, 2002. p. 13-38. p. 16.

${ }^{26}$ BARRAL, Welber. Protecionismo e neoprotecionismo no comércio internacional. In: (Org.). O Brasil e o protecionismo. São Paulo: Aduaneiras, 2002. p. 13-38. p. 17.

${ }^{27}$ BARRAL, Welber. Protecionismo e neoprotecionismo no comércio internacional. In: (Org.). O Brasil e o protecionismo. São Paulo: Aduaneiras, 2002. p. 13-38. p. 17. 
correr com os produtores estrangeiros. Não adotar medidas protecionistas, nessa situação, destruiria a indústria nascente. Adotar medidas protecionistas é dar uma sobrevida a essa indústria nascente, o que nem sempre gera efeitos necessariamente benéficos sobre a economia nacional..$^{28}$

Por fim, justifica-se a adoção de medidas protecionistas para a defesa de valores imateriais da sociedade, isto é, para impedir que certos padrões da sociedade sejam atingidos por padrões de produtos importados. São razões religiosas, morais ou culturais que justificariam a imposição de barreiras, bem como a defesa da segurança nacional, da saúde pública e do consumidor. ${ }^{29}$

Qualquer que seja a justificativa, o efeito buscado com o protecionismo é o estímulo à produção local, por meio da redução da competitividade do produto importado. ${ }^{30}$ No entanto, é certo que esse efeito nem sempre é alcançado, tendo em vista os diversos fatores que influenciam a concorrência em relação a determinado produto.

Além disso, outros efeitos podem ser gerados com a adoção de medidas protecionistas, como por exemplo, podem-se afetar os preços mundiais do produto, no caso de concessão de um subsídio relevante por um grande exportador. Outrossim, a adoção de medidas protecionistas também pode afetar a balança comercial de um país, reduzindo a saída de recursos para importações, ou aumentando o ingresso de recursos para pagamento de tributos. Ademais, a adoção de medidas protecionistas pode gerar contramedidas, reações por parte dos afetados e ainda afetar os custos de eficiência do país importador. ${ }^{31}$

${ }^{28}$ NUSDEO, Fábio. Curso de economia: introdução ao direito econômico. São Paulo: RT, 1997. p. 392; BARRAL, Welber. Protecionismo e neoprotecionismo no comércio internacional. In: (Org.). O Brasil e o protecionismo. São Paulo: Aduaneiras, 2002. p. 13-38. p. 18.

${ }^{29}$ BARRAL, Welber. Protecionismo e neoprotecionismo no comércio internacional. In: (Org.). O Brasil e o protecionismo. São Paulo: Aduaneiras, 2002. p. 13-38. p. 19.

${ }^{30}$ BARRAL, Welber. Protecionismo e neoprotecionismo no comércio internacional. In: (Org.). O Brasil e o protecionismo. São Paulo: Aduaneiras, 2002. p. 13-38. p. 21.

${ }^{31}$ BARRAL, Welber. Protecionismo e neoprotecionismo no comércio internacional. In: (Org.). O Brasil e o protecionismo. São Paulo: Aduaneiras, 2002. p. 13-38. p. 22-23. 
Prismas: Dir., Pol. Publ. e Mundial., Brasília, v. 7, n. 2, p. 59-85, jul./dez. 2010 A necessidade de regulamentação multilaretal do comércio internacional ...

\subsection{Liberalização do comércio}

Apesar de todas as justificativas que podem ser apresentadas e até dos eventuais efeitos desejados, é certo que as medidas protecionistas nunca foram aceitas de modo pacífico. Não é fácil definir qual a extensão exata a ser dada às medidas protecionistas, nem quem deve ser beneficiado por elas, nem sua duração. ${ }^{32}$

Desde sempre, houve oposição à adoção de tais medidas, não só pelos possíveis efeitos negativos das mesmas, mas, sobretudo, pelos efeitos benéficos do livre comércio, concebido como o melhor instrumento para desenvolver o comércio e promover o progresso da nação, ${ }^{33}$ beneficiando em especial os consumidores nacionais.

Impor barreiras ao fluxo de mercadorias aumenta o custo dessas mercadorias, o que afeta diretamente o consumidor, que terá que gastar mais para ter acesso a elas. Tal sacrifício não se justifica, a não ser em função de interesses maiores em jogo. Além disso, tais medidas podem gerar efeitos negativos sobre a economia do país como um todo, tendo em vista que a proteção de uma indústria ineficiente, por exemplo, pode gerar custos irreparáveis, sem benefícios em contrapartida. ${ }^{34}$

De outro lado, o livre comércio traz vantagens aos consumidores, na medida em que lhes dá acesso aos produtos com melhor preço, sejam eles fabricados internamente, sejam importados em melhores condições. Ora, se há melhores condições de importar um produto do que fabricá-lo internamente, não há motivo para impedir ou impor barreiras a essa importação, desde que os benefícios para o consumidor sejam maiores do que os prejuízos dos produtores nacionais. Estabelece-se assim a harmonia geral dos interesses, sacrificando o interesse da minoria em função de benefícios para a maioria. ${ }^{35}$

32 ALMEIDA, Paulo Roberto de. O Brasil e o multilateralismo econômico. Porto Alegre: Livraria do Advogado, 1999. p. 195.

${ }^{33}$ BARRAL, Welber. Protecionismo e neoprotecionismo no comércio internacional. In: (Org.). O Brasil e o protecionismo. São Paulo: Aduaneiras, 2002. p. 13-38. p. 13.

${ }^{34}$ BARRAL, Welber. Protecionismo e neoprotecionismo no comércio internacional. In: (Org.). O Brasil e o protecionismo. São Paulo: Aduaneiras, 2002. p. 13-38. p. 18.

${ }_{35}$ ANNONI, Danielle. Protecionismo regulatório e comércio internacional. In: BARRAL, Welber. O Brasil e o protecionismo. São Paulo: Aduaneiras, 2002. p. 39-59. p. 42. 
Esses benefícios ao consumidor só poderiam ser obtidos num sistema de livre comércio, no qual ao acesso aos produtos não é modificado por medidas protecionistas. Assim sendo, não se poderiam impor barreiras ao fluxo de mercadorias, porquanto tais barreiras aumentariam o custo dos produtos, gerando prejuízos aos consumidores sem a existência de benefícios que justificassem a imposição das barreiras.

Outrossim, é certo que a liberalização do comércio milita em favor da especialização dos países, com a adoção de uma produção em uma economia de escala. Mais uma vez, a teoria das vantagens comparativas explica esse fenômeno, quando afirma que será "sempre mais vantajoso trocar os bens produzidos internamente em melhores condições por outros importados de terceiros países, por sua vez, mais bem dotados com relação a tais produtos" ${ }^{36}$ Cada Estado deveria se especializar naquilo que tem melhores condições de fazer, o que gerará benefícios para todo o mundo, tendo em vista a utilização mais racional dos recursos, com os quais cada país foi dotado.

Ressalte-se, desde já, que mesmo a orientação pró-liberalização exige a instituição de um corpo normativo, que tenha como valor primordial a liberalização do comércio. É apenas parcialmente correta a afirmação de que a liberalização do comércio exige a ausência de normas restritivas, pois, além da ausência de normas restritivas, é essencial a existência de normas que garantam os princípios e os valores do livre comércio. ${ }^{37} \mathrm{O}$ que deve ocorrer é a substituição gradual de normas nacionais mais restritivas, por normas internacionais mais liberais. ${ }^{38}$

\footnotetext{
${ }^{36}$ NUSDEO, Fábio. Curso de economia: introdução ao direito econômico. São Paulo: RT, 1997. p. 372-373.

${ }^{37}$ NASSER, Rabih Ali. A liberalização do comércio internacional nas normas do GATTOMC. São Paulo: Ltr, 1999. p. 44-45.

${ }^{38}$ NASSER, Rabih Ali. A liberalização do comércio internacional nas normas do GATTOMC. São Paulo: Ltr, 1999. p. 47.
} 


\subsection{Regulamentação atual: do bilateralismo ao multilateralismo}

Mesmo antes da expansão da globalização, é certo que já se apresentava certa relação de complementaridade entre as economias de vários países, a qual se instrumentalizava por meio dos chamados acordos de comércio, também denominados "tratados de amizade comércio e navegação" ${ }^{39}$ Esses acordos bilaterais representavam o instrumento mais frequente de regulamentação da cooperação econômica e técnica entre os países, até meados do século XX. Tais acordos visam, em um primeiro momento, obter a redução de tarifas de importação, dando certa previsibilidade aos agentes particulares nas transações bilaterais. ${ }^{40}$

Apesar dessa tendência, não se pode negar que já existiam certas uniões internacionais de cooperação, as quais, todavia, não tiveram grande êxito no desempenho do seu papel. Já no fim do século XIX, foram tomadas algumas iniciativas, ainda tímidas, no sentido de uma regulamentação multilateral do comércio. Embora já existissem certas iniciativas no sentido de uma regulamentação multilateral do comércio, nada se realizou de modo substantivo, prevalecendo o bilateralismo ou mesmo a guerra comercial. ${ }^{41}$

Com a crise de 1929, tal tendência se reforçou ainda mais, sobretudo porque ela desencadeou uma série de medidas protecionistas por parte dos Estados Unidos, com o intuito de proteger os seus mercados, além de promoverem o quase fechamento de suas fronteiras por meio de uma restrição muito forte das importações. ${ }^{42}$ Há nesse período uma conduta que persiste até hoje e, de certo modo, representa um entrave para a uma maior abertura nas relações comerciais internacionais.

${ }^{39}$ ALMEIDA, Paulo Roberto de. O Brasil e o multilateralismo econômico. Porto Alegre: Livraria do Advogado, 1999. p. 39.

${ }^{40}$ LUPI, André Lipp Pinto Basto. Soberania, OMC e Mercosul. São Paulo: Aduaneiras, 2001. p. 138.

${ }^{41}$ ALMEIDA, Paulo Roberto de. O Brasil e o multilateralismo econômico. Porto Alegre: Livraria do Advogado, 1999. p. 81.

${ }^{42}$ FALCÃO, Maurin Almeida. Livre-comércio: que contexto político? Aspectos históricos das dificuldades dos países em desenvolvimento ou em transição, no acesso a mercados. Revista do Programa de Mestrado em Direito do UniCEUB, Brasília, v. 2, n. 2, p. 1-11, jul./ dez. 2005. 
Após a Segunda Guerra Mundial, é certo que outra realidade se põe para o mundo. "O fracasso da Sociedade das Nações que, aliado ao recrudescimento do protecionismo comercial e à depressão econômica dos anos trinta, influenciariam as ações tomadas após $1945 "{ }^{43}$ Os problemas do período entre guerras, marcado pelo protecionismo econômico e pelo nacionalismo, fizeram surgir uma união em torno de objetivos comuns, com o intuito de reduzir as tensões econômicas e políticas, preservando a paz e buscando melhorar o bem estar da população. ${ }^{44}$

Especialmente após 1960, começam a se difundir os acordos multilaterais de comércio, suplantando os acordos bilaterais, como mecanismos reguladores da vida econômica das nações. ${ }^{45}$ Os Estados cedem parte de suas competências reguladoras para entidades de âmbito supranacional ou intergovernamental, para uma administração concentrada de certos setores da vida econômica, em especial do comércio. ${ }^{46}$

A Conferência de Bretton Woods, em 1944, é o marco inicial desse processo de regulamentação multilateral do comércio, tendo como pilares fundamentais a cláusula da nação mais favorecida e a cláusula do tratamento nacional, ${ }^{47}$ que são corolários do princípio da não discriminação. Nessa Conferência, foram propostas as criações do Fundo Monetário Internacional (FMI), do Banco Internacional para Reconstrução e Desenvolvimento (BIRD ou Banco Mundial) e da Organização Internacional do Comércio (OIC), cada um com funções específicas, para organizar o desenvolvimento global.

\footnotetext{
${ }^{43}$ FALCÃO, Maurin Almeida. Livre-comércio: que contexto político? Aspectos históricos das dificuldades dos países em desenvolvimento ou em transição, no acesso a mercados. Revista do Programa de Mestrado em Direito do UniCEUB, Brasília, v. 2, n. 2, p. 1-11, jul./ dez. 2005.

${ }^{44}$ NASSER, Rabih Ali. A liberalização do comércio internacional nas normas do GATTOMC. São Paulo: Ltr, 1999. p. 22.

${ }^{45}$ ALMEIDA, Paulo Roberto de. O Brasil e o multilateralismo econômico. Porto Alegre: Livraria do Advogado, 1999. p. 84.

${ }^{46}$ ALMEIDA, Paulo Roberto de. O Brasil e o multilateralismo econômico. Porto Alegre: Livraria do Advogado, 1999. p. 85.

${ }^{47}$ FALCÃO, Maurin Almeida. Livre-comércio: que contexto político? Aspectos históricos das dificuldades dos países em desenvolvimento ou em transição, no acesso a mercados. Revista do Programa de Mestrado em Direito do UniCEUB, Brasília, v. 2, n. 2, p. 1-11, jul./ dez. 2005. p.
} 
Apesar do fracasso parcial dessa Conferência, uma vez que não foi instituída a OIC - Organização Internacional do Comércio, ocorreram grandes avanços no sentido de uma regulamentação multilateral do comércio.

Os países preferiram realizar negociações para reduções tarifárias globais, criando o chamado Acordo Geral sobre Tarifas e Comércio (GATT). O GATT era um tratado genérico que abrangia diversos temas. Tal tratado sempre foi provisório, na medida em que esperava pela criação de uma organização internacional. Além disso, o GATT nunca teve uma base institucional, não tendo poderes para tomar deliberações ao arrepio da vontade dos Estados. Apesar disso, ele passou a funcionar, de forma provisória, como um organismo internacional que, no entanto, nunca teve o poder suficiente para impedir que seus signatários se desviassem por caminhos protecionistas.

Ao invés de se criar um fórum permanente de negociações, restou aos países a opção de fazer rodadas localizadas de negociações, nas quais cada uma durava vários anos e novos temas eram incorporados a ela. A rodada Uruguai, iniciada em setembro de 1986 em Punta Del Este e finalizada em abril de 1994 em Marraqueche; teve como grande resultado a criação da OMC - Organização Mundial do Comércio, organização internacional que constitui em um fórum permanente de negociações, com base institucional e uma estrutura administrativa, suprindo boa parte das lacunas então existentes. Com a criação da OMC, surge toda uma regulamentação multilateral do comércio internacional, por meio dos chamados acordos da rodada Uruguai.

A Organização Mundial do Comércio - OMC, que passou a funcionar em 1995, tem como objetivo, ao menos formalmente, "a expansão da produção e do comércio de bens e serviços, a partir de uma proposta de desenvolvimento sustentável", ${ }^{8}$ buscando, em última análise, a liberalização do comércio, alcançando e fortalecendo a liberdade de iniciativa no âmbito internacional, ${ }^{49}$ o que denotaria o viés pró-liberalização da regulamentação atual do comércio.

${ }^{48}$ PRAZERES, Tatiana Lacerda. Comércio internacional e protecionismo: as barreiras técnicas na OMC. São Paulo: Aduaneiras, 2003. p. 35.

${ }^{49}$ NASSER, Rabih Ali. A liberalização do comércio internacional nas normas do GATTOMC. São Paulo: Ltr, 1999. p. 48. 


\section{Princípios da regulamentação multilateral do comércio}

Os chamados acordos da OMC, que englobam o GATT de 1947 e os resultados da Rodada Uruguai, contêm 29 textos jurídicos individuais e 25 entendimentos, decisões e declarações ministeriais, fixam as regras que devem ser observadas no jogo do comércio internacional, de modo a garantir condições gerais de competição aos produtores estrangeiros nos mercados externos. Tais normas são pautadas pelos próprios objetivos da OMC, fundado nos princípios da não discriminação, da igualdade de tratamento, da limitação tarifária, da transparência e da proibição das restrições quantitativas.

Pelo princípio da não discriminação, um Estado deve dar o mesmo tratamento a outros Estados, não deve, a princípio, haver discriminações. ${ }^{50} \mathrm{O}$ que for concedido a um Estado deve ser concedido aos demais. Não deve haver tratamentos preferenciais entre Estados, deve haver um tratamento igualitário. Tal princípio se efetiva, sobretudo, por meio da aplicação da cláusula da nação mais favorecida, pela qual o tratamento favorável que for concedido a um país deve ser estendido a todos os outros. ${ }^{51}$

O princípio da igualdade de tratamento consagra a necessidade de tratamento igual entre produtos importados e produtos nacionais similares, no que tange a tributos ou a outros encargos..$^{52}$ Esse princípio visa garantir um tratamento igualitário entre produtos nacionais e estrangeiros, de modo que a concorrência possa ocorrer livremente. ${ }^{53}$ Em última análise, afirma-se que o lugar onde o produto é fabricado não é critério idôneo para justificar um tratamento diferenciado.

${ }^{50}$ OLIVEIRA, Odete Maria de. Relações comerciais globais e o império dos mercados mundiais. In: OLIVEIRA, Odete Maria de; DAL RI JÚNIOR, Arno (Org.). Direito internacional econômico em expansão: desafios e dilemas. Ijuí: Unijuí, 2003. p. 843-951. p. 910.

${ }^{51}$ LUPI, André Lipp Pinto Basto. Soberania, OMC e Mercosul. São Paulo: Aduaneiras, 2001. p. 168.

${ }^{52}$ OLIVEIRA, Odete Maria de. Relações comerciais globais e o império dos mercados mundiais. In: OLIVEIRA, Odete Maria de; DAL RI JÚNIOR, Arno (Org.). Direito internacional econômico em expansão: desafios e dilemas. Ijuí: Unijuí, 2003. p. 843-951. p. 911-912.

$\underline{53}$ NASSER, Rabih Ali. A liberalização do comércio internacional nas normas do GATTOMC. São Paulo: Ltr, 1999. p. 72. 
Não se pode pretender a imediata abolição de todas as restrições a importações de mercadorias, o que seria faticamente inviável. Todavia, é certo que se pode estabelecer como princípio o respeito a limites máximos, ou seja, a imposição de tarifas à importação deve ter um teto. ${ }^{54}$

Pelo princípio da proibição das restrições quantitativas, o que se objetiva é evitar as restriçõoes não alfandegárias ao comércio, uma vez que tais restrições são menos perceptíveis e mais dificilmente controláveis. ${ }^{55}$ Tolerar livremente tais barreiras seria facilitar a adoção de medidas que iriam contra todo o intuito de liberalização do comércio.

Em complemento a esses princípios, surge o princípio da transparência, que exige comunicações à $\mathrm{OMC}$ sobre todas as medidas que possam afetar direta ou indiretamente o comércio dos Estados membros. ${ }^{56}$ Em função desse princípio, surge a obrigação de dar publicidade às medidas adotadas, permitindo que os Estados tenham conhecimento delas e se familiarizem com elas. Trata-se de uma medida essencial no processo de construção das relações de confiança entre os Estados membros. ${ }^{57}$

A liberalização do comércio é um valor inerente à regulamentação multilateral e, por isso, pauta suas normas e princípios. ${ }^{58}$ Todavia, tal viés não é absoluto, sendo objeto de uma série de exceções.

54 PRAZERES, Tatiana Lacerda. Comércio internacional e protecionismo: as barreiras técnicas na OMC. São Paulo: Aduaneiras, 2003. p. 43.

${ }^{55}$ NASSER, Rabih Ali. A liberalização do comércio internacional nas normas do GATTOMC. São Paulo: Ltr, 1999, p. 77.

${ }^{56}$ OLIVEIRA, Odete Maria de. Relações comerciais globais e o império dos mercados mundiais. In: OLIVEIRA, Odete Maria de e DAL RI JÚNIOR, Arno (Org.). Direito internacional econômico em expansão: desafios e dilemas. Ijuí: Unijuí, 2003. p. 912; LUPI, André Lipp Pinto Basto. Soberania, OMC e Mercosul. São Paulo: Aduaneiras, 2001. p. 170.

${ }^{57}$ PRAZERES, Tatiana Lacerda. Comércio internacional e protecionismo: as barreiras técnicas na OMC. São Paulo: Aduaneiras, 2003. p. 45.

${ }^{58}$ NASSER, Rabih Ali. A liberalização do comércio internacional nas normas do GATTOMC. São Paulo: Ltr, 1999, p. 13. 


\section{As concessões protecionistas}

Embora seja tido como um modelo ideal, o ideário de livre comércio não é absoluto, isto é, a liberalização do comércio internacional comporta exceções. Qualquer Estado fica sujeito ocasionalmente a pressões de grupos em busca de um tratamento especial ${ }^{59} \mathrm{e}$, por vezes, esse tratamento pode até ser justificável. Tais medidas se mostram como condições para se alcançar progressivamente a liberalização ${ }^{60}$ e torná-la politicamente possível, ${ }^{61}$ daí até falar-se em princípio da flexibilidade. ${ }^{62}$

As exceções ao livre comércio podem ser agrupadas em três classes: medidas de defesa comercial (salvaguardas, medidas compensatórias, medidas antidumping); exceções permanentes (exceções gerais, waivers, razões de segurança nacional e renegociação de concessões) e exceções contingenciais (exceção da balança de pagamentos e exceção da indústria nascente). ${ }^{63}$ Todas essas exceções são regulamentadas em regras de um sistema multilateral de comércio, a fim de evitar discriminações e a imposição de restrições veladas ao livre comércio.

As medidas de defesa comercial, em geral, justificam-se para proteger a indústria nacional contra a concorrência de produtos importados. ${ }^{64}$ Tais medidas podem ser adotadas em condições especiais, respondendo a situações emergenciais ou a um dano causado à indústria nacional. ${ }^{65}$

${ }^{59}$ BROGINI, Gilvan. Defesa comercial e protecionismo. In: BARRAL, Welber. (Org.). O Brasil e o protecionismo. São Paulo: Aduaneiras, 2002. p. 139-169. p. 140.

${ }^{60}$ SAUVÉ, Pierre. Completing the Gats Framework. In: HOEKMAN, B., MATTOO, A. ENGLISH, Philip (Ed.). Development, trade, and the WTO. Washington: Bird, 2002. p.326-335. p.327.

${ }^{61}$ HOEKMAN, Bernard M.; KOSTECKI, Michel M. The political economy of the world trading system: the WTO and beyond. 2. ed. Londres: Oxford University, 2001. p. 342.

${ }^{62}$ OLIVEIRA, Odete Maria de. Relações comerciais globais e o império dos mercados mundiais. In: OLIVEIRA, Odete Maria de; DAL RI JÚNIOR, Arno (Org.). Direito internacional econômico em expansão: desafios e dilemas. Ijuí: Unijuí, 2003. p. 843-951. p. $910-913$.

${ }^{63}$ BARRAL, Welber. Protecionismo e neoprotecionismo no comércio internacional. In: (Org.). O Brasil e o protecionismo. São Paulo: Aduaneiras, 2002. p. 13-38. p. 28-30.

${ }^{64}$ BROGINI, Gilvan. Defesa comercial e protecionismo. In: BARRAL, Welber. (Org.). O Brasil e o protecionismo. São Paulo: Aduaneiras, 2002. p. 139-169. p. 140.

${ }^{65}$ ALMEIDA, Paulo Roberto de. O Brasil e o multilateralismo econômico. Porto Alegre: Livraria do Advogado, 1999. p. 208. 
A tomada de medidas antidumping é uma medida protecionista tomada pelos Estados diante de uma prática comercial denominada dumping que representa uma venda de produtos por preços inferiores ao seu preço de custo. ${ }^{66}$ Trata-se de uma barreira comercial justificada pela deslealdade da prática do dumping e regulamentada pelo Acordo Antidumping da Rodada Uruguai. Para a tomada das medidas antidumping, são necessárias três fases: a verificação da prática do dumping, a avaliação econômica e o juízo de conveniência e oportunidade diante do caso concreto. ${ }^{67}$

As medidas compensatórias, por sua vez, são tomadas como uma resposta diante de subsídios prejudiciais adotados pelo país exportador e se justificam em primeiro lugar, porque os subsídios introduzem uma distorção no comércio mundial e em segundo lugar, porque eles representam uma distorção na competição internacional. ${ }^{68}$

$\mathrm{Na}$ adoção de salvaguardas, o que se busca é a proteção do interesse econômico nacional. ${ }^{69}$ Em sentido específico, as salvaguardas podem ser entendidas como "o mecanismo de defesa comercial através do qual um país importador pode em casos de urgência e por tempo determinado, suspender as concessões tarifárias para determinado produto ou limitar (quantitativamente) sua entrada, caso verifique um aumento brusco e repentino nas importações de tal produto, e que isto não está sendo suportado materialmente pela indústria nacional".70 As salvaguardas servem para permitir que a indústria nacional afetada bruscamente pelo aumento na importação de produtos concorrentes se ajuste e possa competir. Não se exige aqui qualquer análise de deslealdade da conduta e sua adoção em caráter geral

${ }^{66}$ HOEKMAN, Bernard M.; KOSTECKI, Michel M. The political economy of the world trading system: the WTO and beyond. 2. ed. Londres: Oxford University, 2001. p. 315

${ }^{67}$ BARROS, Maria Carolina Mendonça de. Antidumping e protecionismo. São Paulo: Aduaneiras, 2004. p. 37

${ }^{68}$ HOEKMAN, Bernard M.; KOSTECKI, Michel M. The political economy of the world trading system: the WTO and beyond. 2. ed. Londres: Oxford University, 2001. p. 213.

${ }^{69}$ FINGER, J. Michael. Safeguards. In: HOEKMAN, B., MATTOO, A. ENGLISH, Philip (Ed.). Development, trade, and the WTO. Washington: Bird, 2002. p. 203.

${ }^{70}$ BROGINI, Gilvan. Medidas de salvagurada. In: BARRAL, Welber. In: (Org.). $O$ Brasil e a OMC. 2. ed. Curitiba: Juruá, 2004. p. 252. 
pode gerar transtornos políticos que nem sempre se quer enfrentar. ${ }^{71} \mathrm{~A}$ aplicação das medidas de salvaguarda deve ser limitada no tempo, sendo progressivamente retirada e algumas são sujeitas às demandas de compensação. ${ }^{72}$

As exceções permanentes podem ser invocadas a qualquer tempo e se justificam, em tese por valores maiores em jogo, dignos de proteção no confronto com os valores do livre comércio. O exemplo mais claro da ideia das exceções permanentes é a defesa da segurança nacional.

As exceções gerais são medidas para resguardar a moral e a saúde pública, normas internas e recursos naturais. ${ }^{73}$ Em todo caso, elas só podem ser aplicadas se não representarem uma discriminação arbitrária entre Estados e nem uma restrição velada ao livre comércio.

Os waivers são dispensas do cumprimento de certas obrigações assumidas no âmbito do sistema multilateral de comércio, que devem ser autorizadas pela conferência ministerial da OMC. ${ }^{74}$ Em qualquer caso, os waivers são limitados no tempo e devem ser revistos anualmente para verificar se as circunstâncias excepcionais que justificaram a sua concessão se mantêm. ${ }^{75}$

Por fim, representam exceções permanentes autorizadas, as renegociações das concessões tarifárias entre determinados Estados. Tais exceções se aplicam no caso de o Estado ter assumido compromissos de liberalização do comércio de

${ }^{71}$ BROGINI, Gilvan. Defesa comercial e protecionismo. In: BARRAL, Welber. (Org.). O Brasil e o protecionismo. São Paulo: Aduaneiras, 2002. p. 139-169. p. 150.

72 SAUVÉ, Pierre. Completing the Gats Framework. In: HOEKMAN, B., MATTOO, A. ENGLISH, Philip (Ed.). Development, trade, and the WTO. Washington: Bird, 2002. p.326-335.

${ }^{73}$ HOEKMAN, Bernard M.; KOSTECKI, Michel M. The political economy of the world trading system: the WTO and beyond. 2. ed. Londres: Oxford University, 2001. p. 304.

${ }^{74}$ BARRAL, Welber. Protecionismo e neoprotecionismo no comércio internacional. In: (Org.). O Brasil e o protecionismo. São Paulo: Aduaneiras, 2002. p. 13-38. p. 29.

${ }^{75}$ HOEKMAN, Bernard M.; KOSTECKI, Michel M. The political economy of the world trading system: the WTO and beyond. 2. ed. Londres: Oxford University, 2001. p. 310. 
determinados, cuja importação excessiva possa causar prejuízos à indústria nacional de produtos similares. ${ }^{76}$

Há ainda as chamadas exceções contingenciais, que podem ser impostas em função de determinadas contingências econômicas. ${ }^{77}$ Estas podem ser invocadas para a defesa da estrutura financeira do Estado, isto é, a fim de resguardar a sua posição financeira no exterior e o equilíbrio de sua balança de pagamentos. Além disso, as exceções contingenciais também podem ser invocadas para a proteção de indústrias nascentes em países em desenvolvimento como uma medida assistencial para o desenvolvimento econômico. ${ }^{78}$

Em todos esses casos, o que se admite é um tratamento excepcional. A intenção é que apenas quando ocorrer uma distorção do comércio internacional que cause prejuízos relevantes, sejam desconsiderados os objetivos da liberalização, admitindo-se medidas protecionistas. ${ }^{79}$ Apenas nessas condições, é que devem ser admitidas as exceções à liberalização.

\section{Conclusão}

A atividade comercial é uma realidade extremamente antiga, inclusive no que diz respeito às relações internacionais, e sempre vem se desenvolvendo. Nesse desenvolvimento da atividade comercial a relação de complementaridade entre as várias economias nacionais se mostrou patente, gerando inclusive a celebração de diversos acordos bilaterais sobre a atividade comercial, em especial pelas vantagens comparativas de cada nação.

${ }^{76}$ NASSER, Rabih Ali. A liberalização do comércio internacional nas normas do GATTOMC. São Paulo: Ltr, 1999. p. 90.

77 BARRAL, Welber. Protecionismo e neoprotecionismo no comércio internacional. In: (Org.). O Brasil e o protecionismo. São Paulo: Aduaneiras, 2002. p. 13-38. p. 30.

${ }^{78}$ HOEKMAN, Bernard M.; KOSTECKI, Michel M. The political economy of the world trading system: the WTO and beyond. 2. ed. Londres: Oxford University, 2001. p. 303.

${ }^{79}$ NASSER, Rabih Ali. A liberalização do comércio internacional nas normas do GATTOMC. São Paulo: Ltr, 1999. p. 96. 
Com a globalização econômica que vem sendo experimentada pelo mundo, tal relação de complementaridade fica cada vez mais forte, podendo-se falar em interdependência das várias economias nacionais. Essa interdependência que não se limita mais a dois países, mas se expande em escala global, exige a adoção de uma regulamentação das relações comerciais internacionais. Tal regulamentação não pode ser mais bilateral, como já havia ocorrido, devendo adotar um aspecto multilateral.

A conferência de Bretton Woods, em 1944, é o marco inicial desse processo de regulamentação multilateral do comércio, que culmina com a criação da OMC. $\mathrm{Na}$ regulamentação multilateral que se apresenta, a liberalização do comércio é erigida como valor fundamental em oposição ao protecionismo, que pautou boa parte das regulamentações bilaterais do comércio internacional.

São estabelecidas em nível internacional as regras que devem ser observadas no jogo do comércio internacional, de modo a garantir condições gerais de competição aos produtores estrangeiros nos mercados externos. Tais normas são pautadas pelos próprios objetivos da $\mathrm{OMC}$, fundado nos princípios da não discriminação, da igualdade de tratamento, da limitação tarifária, da transparência e da proibição das restrições quantitativas. Trata-se de uma resposta aos problemas do período entre guerras e de uma busca de paz entre as nações e de um desenvolvimento sustentável.

A tendência pró-liberalização que decorre da realidade atual do mundo, em especial da interdependência entre as várias economias nacionais, não pode olvidar as realidades diferentes dos diversos países. Em função disso, os princípios da liberalização não podem ser adotados de forma absoluta, devendo comportar exceções que se justifiquem para evitar uma distorção do comércio. Tais exceções, embora protecionistas, mostram-se como condições para se alcançar progressivamente a liberalização e torná-la politicamente possível, diante das diferentes realidades do mundo. 


\section{The need for multilateral regulation in international trade: protectionism $\mathrm{x}$ liberalization}

\section{Abstract}

This article aims to show the necessity of the coexistence of free trade with protectionist practices, through the multilateral regulation of trade. The economic globalization discloses a relation of interdependence between the some national economies. This relation of interdependence imposes the existence of international rules that regulate the commercial activities that are developed. There is no reason to talk about deregulation. Such regulation must be multilateral in the light of the current reality of the world. For such multilateral regulation the values that prevail are those of free trade, as a goal to be reached, in search of peace between the nations and of a sustainable development. However, the definition of pro-liberalization values must admit protectionist concessions, in the light of the distinct reality of each one of the countries inserted in the global market.

Keywords: International trade. Globalization.Protectionism.Free trade.Multilateralism.

\section{Referências}

ALMEIDA, Paulo Roberto de. A globalização e o desenvolvimento: vantagens e desvantagens de um processo indomável. In: DI SENA JÚNIOR, Roberto; CHEREM, Mônica Teresa Costa (Org.). Comércio internacional e desenvolvimento: uma perspectiva brasileira. São Paulo: Saraiva, 2004. p. 17-31.

ALMEIDA, Paulo Roberto de. O Brasil e o multilateralismo econômico. Porto Alegre: Livraria do Advogado, 1999.

ANNONI, Danielle. Protecionismo regulatório e comércio internacional. In: BARRAL, Welber. O Brasil e o protecionismo. São Paulo: Aduaneiras, 2002. p. 3959.

BARRAL, Welber. Protecionismo e neoprotecionismo no comércio internacional. In: (Org.). O Brasil e o protecionismo. São Paulo: Aduaneiras, 2002. p. 1338. 
BARROS, Maria Carolina Mendonça de. Antidumping e protecionismo. São Paulo: Aduaneiras, 2004.

BECK, Ulrich. O que é a globalização? Tradução de André Carone. São Paulo: Paz e Terra, 1999.

BHAGWATI, Jagdish. Em defesa da globalização. Tradução de Regina Lyra. Rio de Janeiro: Elsevier, 2004.

BROGINI, Gilvan. Defesa comercial e protecionismo. In: BARRAL, Welber. (Org.). O Brasil e o protecionismo. São Paulo: Aduaneiras, 2002. p. 139-169.

BROGINI, Gilvan. Medidas de salvagurada. In: BARRAL, Welber. (Org.). O Brasil e a OMC. 2. ed. Curitiba: Juruá, 2004.

FALCÃO, Maurin Almeida. Livre-comércio: que contexto político? Aspectos históricos das dificuldades dos países em desenvolvimento ou em transição, no acesso a mercados. Revista do Programa de Mestrado em Direito do UniCEUB, Brasília, v. 2, n. 2, p. 1-11, jul./dez. 2005.

FARIA, José Eduardo. O direito na economia globalizada. São Paulo: Malheiros, 2000 .

FERRAZ, Daniel Amin. Joint venture e contratos internacionais. Belo Horizonte: Mandamentos, 2001.

FINGER, J. Michael. Safeguards. In: HOEKMAN, B., MATTOO, A. ENGLISH, Philip (Ed.). Development, trade, and the WTO. Washington: Bird, 2002.

GALGANO, Francesco. História do direito comercial. Tradução de João Espírito Santo. Lisboa: PF, 1990.

HABERMAS, Jürgen. A constelação pós-nacional: ensaios políticos. Tradução de Márcio Seligmann- Silva. São Paulo: Littera Mundi, 2001.

HOEKMAN, Bernard M.; KOSTECKI, Michel M. The political economy of the world trading system: the WTO and beyond. 2. ed. Londres: Oxford University, 2001.

JELLINEK, Georg. Teoria general del Estado. Traducción por Fernando de Los Rios Urruti. Granada: Comares, 2000. 
KRUGMAN, Paul R. Rethinking international trade. Massachussets: The Mit Press, 1990.

LOCATELLI, Liliana. A proteção ao consumidor como uma barreira ao livre comércio. In: BARRAL, Welber (Org.). O Brasil e o protecionismo. São Paulo: Aduaneiras, 2002. p. 89-116.

LUPI, André Lipp Pinto Basto. Soberania, OMC e Mercosul. São Paulo: Aduaneiras, 2001.

NASSER, Rabih Ali. A liberalização do comércio internacional nas normas do GATT- OMC. São Paulo: Ltr, 1999.

NUSDEO, Ana Maria de Oliveira. Defesa da concorrência e globalização econômica: o controle da concentração de empresas. São Paulo: Malheiros, 2002.

NUSDEO, Fábio. Curso de economia: introdução ao direito econômico. São Paulo: RT, 1997.

OLIVEIRA, Odete Maria de. Relações comerciais globais e o império dos mercados mundiais. In: OLIVEIRA, Odete Maria de; DAL RI JÚNIOR, Arno (Org.). Direito internacional econômico em expansão: desafios e dilemas. Ijuí: Unijuí, 2003. p. 843-951.

PRAZERES, Tatiana Lacerda. Comércio internacional e protecionismo: as barreiras técnicas na OMC. São Paulo: Aduaneiras, 2003.

SAUVÉ, Pierre. Completing the Gats Framework. In: HOEKMAN, B., MATTOO, A. ENGLISH, Philip (Ed.). Development, trade, and the WTO. Washington: Bird, 2002. p. 326-335.

VEDOVE, Giampaolo Dalle. Concentrazioni e gruppi nel diritto antitrus. Padova: CEDAM, 1999.

VIVANTE, Cesare. Instituições de direito comercial. Tradução de J. Alves de Sá. 3. ed. São Paulo: C. Teixeira, 1928. 
